\title{
Milhocina como fonte proteica para produção de bacteriocina por Enterococcus
}

\author{
faecium \\ Milhocin as protein source for bacteriocin production by Enterococcus faecium \\ Milhocina como fuente de proteína para la producción de bacteriocina por Enterococcus faecium
}

Recebido: 20/01/2021 | Revisado: 23/01/2021 | Aceito: 25/01/2021 | Publicado: 02/02/2021

Janaína Schueler

ORCID: https://orcid.org/0000-0001-9841-6757

Universidade Tecnológica Federal do Paraná, Brasil

E-mail: jana_schueler@hotmail.com

Cássia Milena de Souza

ORCID: https://orcid.org/0000-0001-9643-2059

Universidade Estadual de Londrina, Brasil

E-mail: cassiamisouza@gmail.com

Marly Sayuri Katsuda

ORCID: https://orcid.org/0000-0003-2387-7895

Universidade Tecnológica Federal do Paraná, Brasil

E-mail: sayuri@utfpr.edu.br

Márcia Cristina Furlaneto

ORCID: https://orcid.org/0000-0002-1188-1320

Universidade Estadual de Londrina, Brasil E-mail: furlaneto@uel.br

Luciana Furlaneto-Maia

ORCID: https://orcid.org/0000-0002-7164-3391

Universidade Tecnológica Federal do Paraná, Brasil

E-mail: lucianamaia@utfpr.edu.br

\begin{abstract}
Resumo
A produção de bacteriocina por Bactérias Ácido Lácticas tem atraído grande atenção por causa do seu status GRAS (Generally Recognized as Safe), e seu uso potencial como aditivo para a conservação de alimentos. A utilização de substrato com características que forneçam nutrientes necessários porem com reduzido custo, está entre os itens essenciais para produção e uso comercial de bacteriocinas. Portanto, o objetivo deste trabalho foi avaliar a viabilidade da produção de enterocinas, utilizando soro de leite e água de maceração de milho (milhocina) como substrato em 18 e 24 horas de cultivo. Enterococcus faecium (Efm20, Efm22, Efm24, Efm25) e Enterococcus faecalis (Efs27) foram caracterizados quanto à atividade antimicrobiana de enterocinas presentes no sobrenadante de cultivo livre de células (CFS) contra Listeria innocua CLIP 12612. O caráter proteico da substância antimicrobiana foi confirmado, sendo sua atividade inibitória perdida após o tratamento dos CFS com proteases. Em contrapartida a atividade antimicrobiana dos CFS se manteve termoestável após tratamento com calor $\left(80^{\circ} \mathrm{C}\right.$ e $\left.100^{\circ} \mathrm{C}\right)$ e também quando tratado com catalase, o que confirma que essa atividade do CFS não está relacionada com a ação de $\mathrm{H}_{2} \mathrm{O}_{2}$ e ácido láctico (CFS neutralizado com $\mathrm{NaOH}$ ). Pela contagem de células bacterianas (UFC/mL) dos isolados cultivados nos diferentes meios, observou que houve maior quantidade de UFC em MRS com substratos. A atividade antimicrobiana dos CFS obtido dos meios MRS com substrato em comparação com o MRS foram similares quando em difusão em ágar, porém ao quantificar essa atividade observou maiores valores de unidade arbitrária para os CFS obtidos em meio MRS com milhocina em ambos os tempos avaliados 18 e 24 horas. Em conclusão, constatou-se que os substratos testados apresentam grande potencial para serem aplicados na fabricação de bioconservação de produtos alimentícios.
\end{abstract}

Palavras-chave: Enterocina; Maceração de milho; Conservação de alimentos; Enterococcus sp.

\begin{abstract}
The production of bacteriocin by Lactic Acid Bacteria has attracted great attention because of its GRAS (Generally Recognized as Safe) status, and its potential use as an additive for food preservation. The use of substrate with characteristics that provide necessary nutrients, but at a low cost, is among the essential items for the production and commercial use of bacteriocins. Therefore, the objective of this work was to evaluate the viability of the production of enterokines, using whey and corn maceration water (millhocin) as substrate in 18 and 24 hours of cultivation. Enterococcus faecium (Efm20, Efm22, Efm24, Efm25) and Enterococcus faecalis (Efs27) were characterized for the antimicrobial activity of enterocins present in the cell-free supernatant (CFS) against Listeria innocua CLIP 12612. The protein character of the antimicrobial substance was confirmed, its inhibitory activity being lost after the treatment of CFS with proteases. In contrast, the CFS antimicrobial activity remained thermostable after heat
\end{abstract}


treatment $\left(80^{\circ} \mathrm{C}\right.$ and $100^{\circ} \mathrm{C}$ ) and also when treated with catalase, which confirms that this CFS activity is not related to the action of $\mathrm{H}_{2} \mathrm{O}_{2}$ and lactic acid (CFS neutralized with $\left.\mathrm{NaOH}\right)$. Counting bacterial cells $(\mathrm{CFU} / \mathrm{mL})$ of isolates grown in different media, we observed increase of CFU in MRS with substrates. The antimicrobial activity of CFS obtained from MRS media with substrate compared to MRS was similar when diffusing in agar, however, when quantifying this activity, it observed higher values of arbitrary unit for CFS obtained in MRS medium with millhocin at both times evaluated 18 and 24 hours. In conclusion, it was found that the tested substrates have great potential to be applied in the manufacture of bioconservation of food products.

Keywords: Enterocin; Maceration of corn; Food preservation; Enterococcus sp.

\section{Resumen}

La producción de bacteriocina por las bacterias del ácido láctico ha atraído gran atención debido a su estado GRAS (generalmente reconocido como seguro) y su uso potencial como aditivo para la conservación de alimentos. El uso de sustrato con características que aporten los nutrientes necesarios, pero a bajo costo, se encuentra entre los elementos esenciales para la producción y uso comercial de bacteriocinas. Por tanto, el objetivo de este trabajo fue evaluar la viabilidad de la producción de enteroquinas, utilizando como sustrato suero y agua de maceración de maíz (milhocina) en 18 y 24 horas de cultivo. Enterococcus faecium (Efm20, Efm22, Efm24, Efm25) y Enterococcus faecalis (Efs27) se caracterizaron por la actividad antimicrobiana de las enterocinas presentes en el sobrenadante libre de células (CFS) contra Listeria innocua CLIP 12612. Se confirmó el carácter proteico de la sustancia antimicrobiana , perdiéndose su actividad inhibidora después del tratamiento del SFC con proteasas. Por el contrario, la actividad antimicrobiana del CFS se mantuvo termoestable después del tratamiento térmico $\left(80^{\circ} \mathrm{C}\right.$ y $\left.100^{\circ} \mathrm{C}\right)$ y también cuando se trató con catalasa, lo que confirma que esta actividad del CFS no está relacionada con la acción del H2O2 y el ácido láctico ( CFS neutralizado con $\mathrm{NaOH}$ ). Al contar las células bacterianas (UFC / mL) de los aislados cultivados en diferentes medios, observó que había una mayor cantidad de UFC en MRS con sustratos. La actividad antimicrobiana del SFC obtenido a partir de medio MRS con sustrato en comparación con MRS fue similar al difundir en agar, sin embargo, al cuantificar esta actividad se observaron valores más altos de unidad arbitraria para SFC obtenido en medio MRS con milhocina en ambos tiempos evaluados 18 y 24 horas. En conclusión, se encontró que los sustratos probados tienen un gran potencial para ser aplicados en la fabricación de bioconservación de productos alimenticios.

Palabras clave: Enterocina; Maceración de maíz; Conservación de los alimentos; Enterococcus sp.

\section{Introdução}

Bacteriocinas são peptídeos antimicrobianos utilizados na indústria de alimentos e considerados como seguros (GRAS) (Cleveland et al., 2001). As bacteriocinas afetam as bactérias alvo por vários mecanismos, incluindo a formação de poros na membrana celular, a inibição da parede celular ou síntese de proteínas e a degradação do DNA celular (Ozdemir et al., 2011; Ogaki et al., 2016). O aumento do interesse pelas bacteriocinas se deve às suas potentes atividades inibitórias, ao fato de serem seguras para os humanos, à sua estabilidade e aos diversos modos de ação. Além disso, a resistência às bacteriocinas raramente foi observada. Bactérias produtoras de bacteriocinas podem ser isoladas de plantas, animais, alimentos, água e solo (Zendo et al., 2006; Furlaneto-Maia et al., 2020).

Enterocinas são uma classe de bacteriocinas catiônicas produzidas por Enterococcus sp, apresentando resistência a uma ampla de temperaturas e níveis de pH, além de serem facilmente destruídos por proteases digestivas (Tosoni et al., 2019). A vantagem das enterocinas sobre outros peptídeos antimicrobianos, por exemplo nisina, é que este peptídeo pode afetar tanto bactérias Gram positivas quanto negativas, tais como Listeria innocua, Listeria monocytogenes Enterococcus faecalis, Staphylococcus aureus, Salmonella enteritidis, Salmonella typhimurium e Escherichia coli (Ogaki et al., 2016).

Enterocinas podem ser utilizada nos alimentos de duas formas: pela inoculação do isolado bacteriocinogênico como uma cultura bioprotetora ou pela adição da bacteriocina produzida e concentrada. Neste último caso, para eficaz uso comercial da bacteriocina, faz-se necessário a otimização dos processos de produção para tornar o produto economicamente viável (López et al., 2007; Ananou et al., 2008). Porém, o elevado valor de produção e baixo rendimento na obtenção de quantidades significante de enterocina pura, têm limitado sua utilização como conservante de alimentos (López et al., 2007). Ainda, a matriz alimentar tem que ser adequada para o desenvolvimento do microrganismo produtor de enterocina (Ananou et al., 2008). 
Vários pesquisadores têm tentado aperfeiçoar a produção de bacteriocinas em meios de cultura comerciais e em substratos de grau alimentar, tais como leite e soro de leite (ANANOU et al., 2008) e resíduos de produtos da pesca (Vázquez, et al., 2006). Modificações nos componentes dos substratos podem influenciar positivamente a quantidade e a atividade da enterocinas, devendo os mesmos, serem considerados quando da otimização da produção deste peptídeo (Ogaki et al., 2016). Portanto, a utilização de subprodutos da indústria de alimentos pode apresentar uma alternativa para reduzir o custo da produção de enterocina.

Dentre os subprodutos que podem ser utilizados como substratos alternativos podemos citar água de maceração do milho (milhocina), um subproduto que contém elevada quantidade de nitrogênio, aminoácidos entre outros nutrientes. Estudos foram realizados utilizando a milhocina na produção de biosurfatantes (Luna et al., 2008), produção de ácido (Rivas et al., 2004) e utilização na alimentação complementar para aves e ruminantes (Amartey; Leung, 2000).

Pelo disposto acima e enfatizando a crescente utilização de bacteriocinas na conservação de alimentos, esta pesquisa objetivou avaliar a viabilidade da produção de enterocinas, utilizando milhocina como fonte proteica, bem como efetuar um comparativo entre a enterocina produzida por milhocina e em meio de cultura industrial.

\section{Metodologia}

\subsection{Linhagens bacteriana e condição de cultivo}

Neste estudo foram utilizados quatro isolados de E. faecium denominados de Efm20, Efm22 Efm24, Efm25, previamente caracterizados por Ogaki et al (2016). Estes isolados são provientes de alimentos e as culturas se encontram estocadas a $-20{ }^{\circ} \mathrm{C}$. No komento do uso, uma alíquota foi re-hidratadas em caldo MRS (ManRogosa Sharpe - Himedia, Mumbai, India) por 18 horas a $37^{\circ} \mathrm{C}$. A bactéria indicadora Listeria innocua CLIP 12612 foi cultivada em meio BHI (Brain Heart Infusion - Himedia, Mumbai, India).

\subsection{Elaboração do meio de cultivo contendo milhocina}

A patente para o meio contendo milhocina está registrado no inpi com número do processo br 102018068214 8. a composição do meio consta de $15 \mathrm{~g} / \mathrm{l}$ de milhocina (Sigma-aldrich) como fonte proteica, $20 \mathrm{~g} / \mathrm{l}$ glicose, $1 \mathrm{~g} / \mathrm{l}$ tween 80, 5g/l de acetato de sódio e traços de sais de sulfato.

\subsection{Obtenção do sobrenadante livre de células e contagem de células}

O sobrenadante livre de célula (CFS), contendo a enterocina, foi obtido a partir de cada isolado bacteriano em meio de cultura liquido contendo milhocina e meio de cultura MRS-Oxoid como controle. Nos tempos de $18 \mathrm{~h}$ e $24 \mathrm{~h}$ de incubação dos isolados nesses meios, foi retirado $21 \mathrm{~mL}$ do cultivo para a contagem de célula (UFC/mL) e obtenção do sobrenadante livre de células (CFS). A contagem de célula bacteriana foi feita por diluição seriada em $\mathrm{NaCl}(0,85 \%)$ e plaqueadas em BHI ágar. A $\mathrm{UFC} / \mathrm{mL}$ foi calculada após $18 \mathrm{~h}$ de incubação a $37^{\circ} \mathrm{C}$.

A obtenção de CFS seguiu protocolo descrito por Rocha et al (2019). Um volume de $20 \mathrm{~mL}$ de cultivo foi centrifugado a $5000 \mathrm{rpm}$ por 15 minutos e o sobrenadante teve pH ajustado em 6,5 utilizando solução de $\mathrm{NaOH} 1 \mathrm{~N}$ e tratamento com $1 \mathrm{mg} / \mathrm{mL}$ de catalase. O CFS foi esterilizado por filtração em membrana com poros de $0,22 \mu \mathrm{m}$ com baixa capacidade de ligação de proteínas (Millipore).

\subsection{Ensaio da atividade antagonica}

O ensaio da atividade da enterocina foi realizado pelo método de poço difusão em ágar, de acordo com o descrito por Tosoni et al. (2019), com modificações. Um volume de $20 \mathrm{~mL}$ de BHI ágar soft (0,8\%), contendo L. innocua CLIP 12612 na 
concentração final de $1,0 \times 10^{8}$ células $/ \mathrm{mL}$, foi transferido para uma placa de Petri, seguido de tempo de espera para o endurecimento completo do meio. Em seguida, foram realizados poços de aproximadamente 5 mm de diâmetro com auxílio de ponteiras estéreis. Em cada poço foi adicionado $30 \mu \mathrm{L}$ de enterocina, produzida em cada tempo de cultivo. As placas foram mantidas a $20{ }^{\circ} \mathrm{C}$ por $4 \mathrm{~h}$, para permitir a difusão do sobrenadante no ágar e posteriormente foram incubadas a $37{ }^{\circ} \mathrm{C}$ por 24 horas. A atividade antimicrobiana foi detectada visualmente por meio da observação de zonas de inibição clara em torno da estirpe testada. Os halos de inibição foram mensurados em milímetros com auxílio de um paquímetro.

\subsection{Quantificação da atividade antimicrobiana}

A enterocina foi diluída na proporção de 1:2 (v/v) em $\mathrm{NaCl}(0,85 \%)$ esteril, e a ação antagônica foi mensurada pela técnica poço difusão, como descrito anteriormente. A unidade arbitrária (UA) foi expressada como sendo a recíproca da maior diluição que não apresentou crescimento bacteriano, multiplicado por 100 (Mayr-Harting et al., 1972).

\subsection{Estabilidade térmica e tratamento enzimático na atividade antimicrobiana}

A estabilidade térmica da enterocina produzida em milhocina foi avaliado tratando o $\mathrm{CFS}$ a $80{ }^{\circ} \mathrm{C}$ por 10 minutos e a $100{ }^{\circ} \mathrm{C}$ por 20 minutos (Ammor et al., 2006).

Para avaliar a sensibilidade do composto antimicrobiano frente a enzimas proteolíticas, os CFS foram tratados com as enzimas $\alpha$-quimiotripsina, protease e proteinase-K em concentração final de $1 \mathrm{mg} / \mathrm{mL}$. As amostras foram incubadas a $37{ }^{\circ} \mathrm{C}$ por $1 \mathrm{~h}$ (Garriga et al., 1993). A atividade residual foi analisada contra L. innocua pelo método de difusão em ágar, sendo o grupo controle a enterocina sem tratamento.

\subsection{Análise estatistica}

Os valores médios dos halos foram avaliados usando análise de variância one-way (ANOVA) e Tukey's test, considerando $\mathrm{p}<0,05$ para estipular diferenças significativas entre a atividade antimicrobiana dos isolados e controle negativo.

\section{Resultados e Discussão}

E. faecium isolados Efm20, Efm22 Efm24, Efm25 apresentaram crescimento celular superior quando comparado com o meio controle MRS, tanto em 18 e 24 horas de incubação, indicando que a milhocina não impede o desenvolvimento celular de enterococos (Figura 1). 
Figura 1. Crescimento celular mensurado em Unidade Formadora de Colônia dos isolados de Enterococcus faecium em meio contendo milhocina e MRS.

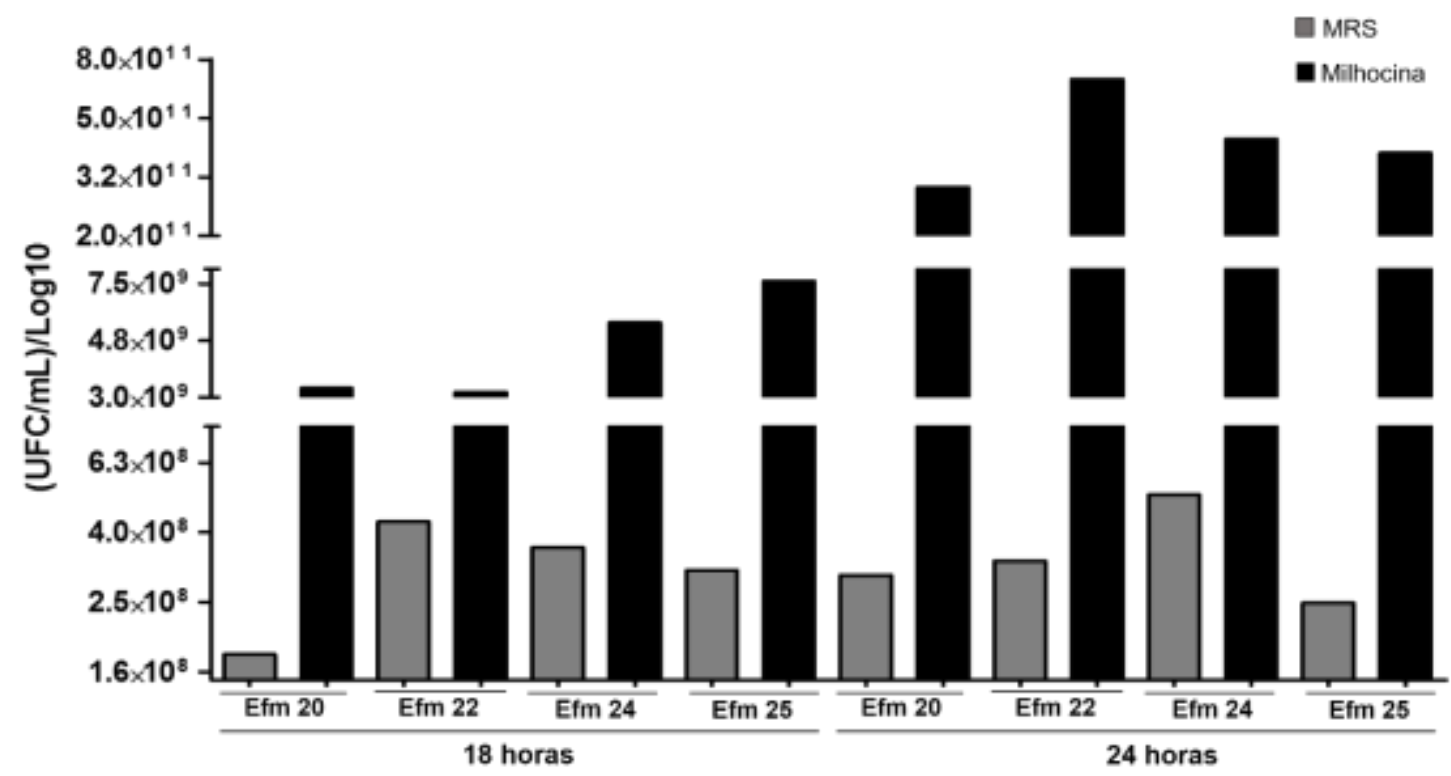

Crescimento celular mensurado em Unidade Formadora de Colônia (UFC) dos isolados de Enterococcus faecium Efm20, Efm22, Efm24 e Efm25 em meio contendo milhocina e MRS, após 18 e 24 h de incubação.

Fonte: Autores (2020).

Em relação a produção de enterocina e inibição de L. innocua observamos que o meio com milhocina apresentou resultados semelhantes ao obtido em MRS; destaque para o isolado Efm22 que apresentou diferença significativa (p<0,05) no halo de inibição da enterocina produzida no meio com milhocina (Figura 2 A), tanto em 18 e 24 h. A atividade antagônica foi mensurando pela técnica poço difusão (Figuras 2 B). Observamos que a enterocina produzidas pelos isolados Efm20, Efm22, Efm24, Efm25 e Efs27 inibiu a bactéria indicadora L. innocua apresentando um halo de inibição ao redor do poço.

Não houve correlação entre crescimento celular e produção. Eficiência de enterocina contra L. innocua.

O número elevado de microrganismos na cultura pode acarretar inibição na produção da bacteriocina, devido ao baixo $\mathrm{pH}$, presença de proteases ou reabsorção pela superfície da célula produtora (Ferreira et al. 2007). Neste estudo essa hipótese foi descartada, pois os isolados apresentaram crescimento maior em em milhocina e continuaram produzindo e inibindo L.innocua em valores semelhantes ao produzido em MRS. Ainda, o isolado Efm22 apresentou maior crescimento em milhocina e maior halo de inibição, mostrando ser um isolado potencial para estudos futuros. 
Figura 2. Atividade antimicrobiana dos isolados de Enterococcus faecium contra Listeria innocua.

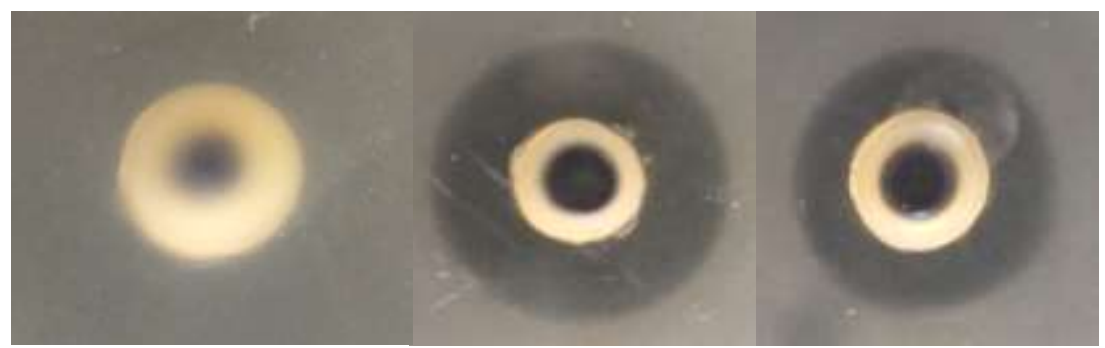

B

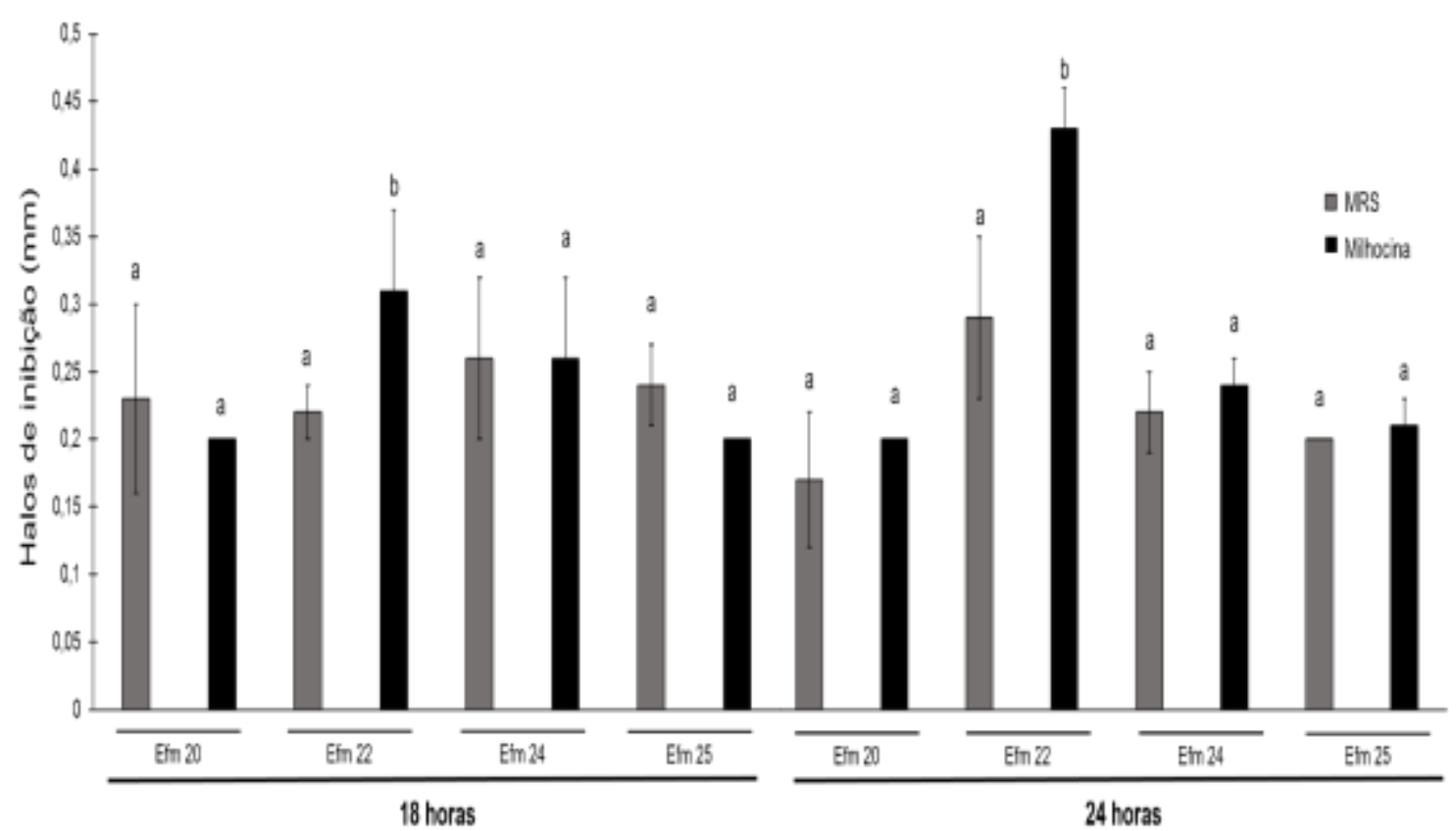

Atividade antimicrobiana dos quatro isolados de Enterococcus faecium contra Listeria innocua conforme medida do halo de inibição em mm (A), após 18 e 24 h de incubação; ensaio poço difusão apresentando o halo de inibição; á esquerda: controle; ao centro: enterocina produzida em MRS; á direita: enterocina produzida em milhocina (B), após 24 h de incubação.

Fonte: Autores (2020).

A presença de ácido láctico no substrato contendo enterocina (CFS), foi descartada ao ajustar o pH em 6,5 utilizando $\mathrm{NaOH}$. Ainda, a utilização de catalase neutralizou a produção de peróxido de hidrogênio, que poderia atuar sobre a membrana citoplasmática das bactérias alvo, causando lesão à célula (Dalié et al., 2010). Ou seja, a inibição das células alvo foi pela ação da enterocina produzida pelos isolados E. faecium.

Motta, Brandelli (2008) e Oliveira et al.,(2012), citam que uma boa fonte de nitrogênio é um diferencial favorável ao crescimento de cepas produtoras de bacteriocinas, porém outros fatores também podem influenciar, tais como $\mathrm{pH}$, temperatura e tempo de incubação.

O valor da UA confirma o potencial antagônico relevante para as enterocinas formadas em milhocina (Figura 3). O teste de diluição seriada nos dá como resultado as unidades arbitrárias (UA/mL). Esse valor é tido como a mais alta diluição capaz de produzir halo de inibição (Salvucci et al., 2019). Também chamado de método de diluição crítica, é muito utilizado para detecção qualitativa e quantitativa de variedades de bacteriocinas (Mayr-Harting et al., 1971). Fato que chama atenção é que mesmo apresentando halo de inibição semelhantes, a UA da enterocina em milhocina foi mais significativa em valores quando comparado á enterocina em MRS, ou seja, pequena quantidade de enterocina pode inibir o crescimento da bactéria indicadora. 
Figura 3. mensuração da Unidade arbitrária de enterocina produzida pelos isolados de Enterococcus faecium

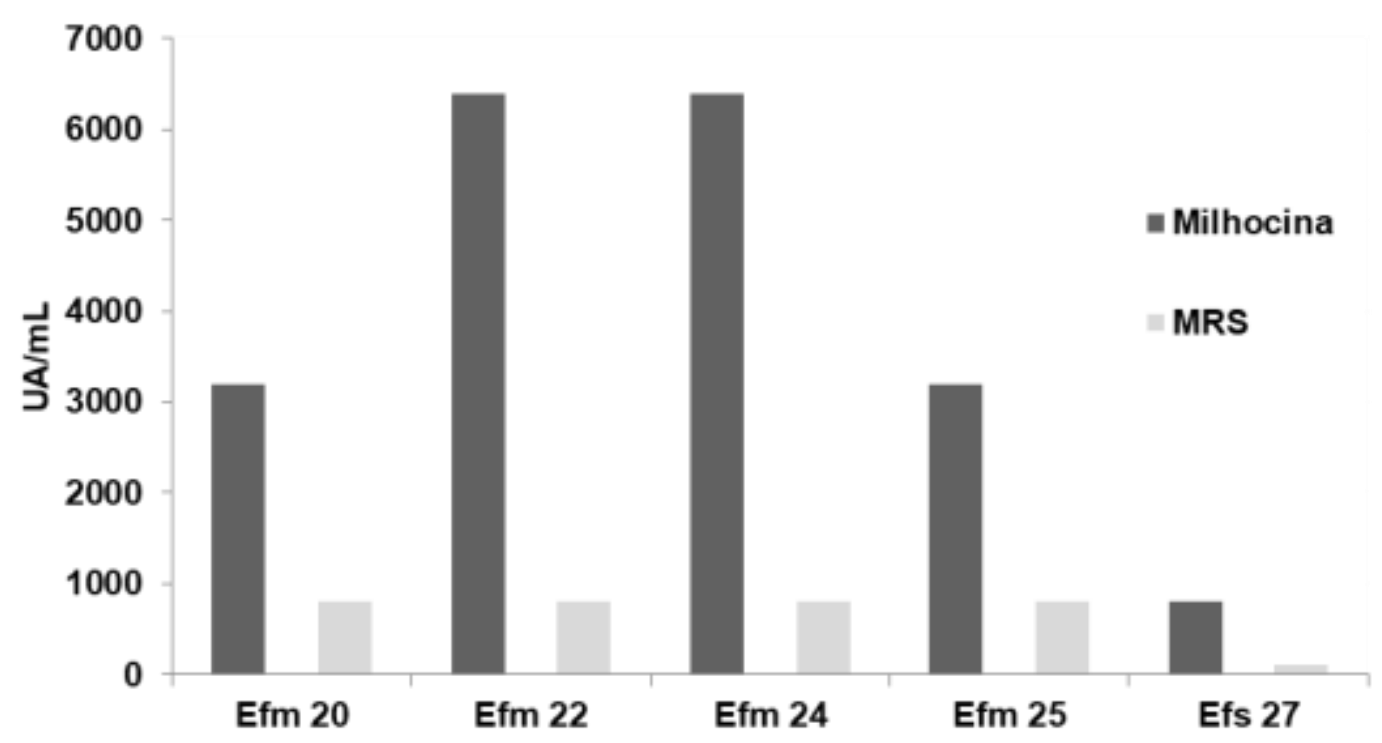

Unidade arbitrária (UA) de enterocina produzida pelos isolados de Enterococcus faecium Efm20, Efm22, Efm24 e Efm25 em meio man Rogosa Sharpe (MRS) e milhocina; Efs foi um isolado controle.

Fonte: Autores (2020).

Os valores obtidos foram muito satisfatórios, pois a literatura relata valores de UA/mL muito inferiores. Ghrairi (2008) obteve um máximo de 380UA/mL, em 17 horas de incubação de E. faecium MMT21 contra cepas de L. monocytogenes. Du et al., (2017) obtiveram valores de 400UA/mL utilizando enterocinas de E.durans contra cepas de L. monocytogenes, em matriz alimentar. Já Motta e Brandelli (2008) obtiveram o máximo de 1600 UA/mL para bacteriocina produzida por Bacillus sp em proteína de soja.

Segundo Bromberg et. al., (2006), os níveis de bacteriocina em CFS raramente excedem 5.000 UA/mL. Este resultado nos indica que o composto antimicrobiano tem um grande potencial de uso como conservador de alimentos.

A enterocina quando tratada com enzimas proteolíticas foi completamente inativada, confirmando assim o caráter proteico corroborando com os estudos realizados por Fouquiér-Moreno et al. (2003), Yang, et al. (2012) e Ogaki et al. (2016). Além disso, após tratamento a $80{ }^{\circ} \mathrm{C}$ por 10 minutos e a $100{ }^{\circ} \mathrm{C}$ por 20 minutos, a atividade antimicrobiana permaneceu estável, tendo a atividade residual em $96 \pm 1,5 \%$. As enterocinas produzidas pelos isolados de E. faecium foi mais estável ao tratamento térmico quando comparado a outras bacteriocinas, como lactocina (Lü et al., 2014) e bacteriocina (Hu et al., 2017).

As características de tolerância ao calor e degradação por enzimas proteolíticas, fazem as enterocinas uma alternativa aos preservativos químicos, uma vez que não causam danos a células eucarióticas, podendo ser facilmente degradadas no estômago (Khan et al., 2010).

\section{Conclusão}

Os isolados de E. faecium apresentaram bom crescimento em meio de cultura contendo milhocina e produziu enterocina com eficiência antagônica semelhante ou superior á produzida em meio MRS. A bacteriocina também apresentou resistência térmica a $100^{\circ} \mathrm{C}$. Os resultados foram muito satisfatórios indicando que um meio de cultura constituído de resíduos agroindustriais apresenta potencialidade na produção de enterocina em escala industrial. 
Estudos futuros propõe testes variando as condições de temperatura e $\mathrm{pH}$ de crescimento do microrganismo no meio contendo milhocina, visando melhorar ainda mais a produção de enterocina. Estes dados serão subsídios para a produção de enterocina em fermentador de bancada.

\section{Agradecimentos}

Ào CNPq, Fundação Araucária (FA), Capes, PROPPG/UTFPR pela infraestrutura e ao Laboratório de Microbiologia Básica e Aplicada (LAMBA) da UTFPR.

\section{Referências}

Amartey, A., \& Leung, J. (2000). Corn steep liquor as a source of nutrients for ethanologic fermentation by Bacillus stearothermophilus t-13. Bulletin of the Chemists and Technologists, 19.

Ammor, S., Tauveron, G., Dufour, E. \& Chevallier, I. (2006). Antibacterial Activity of Lactic Acid Bacteria against Spoilage and Pathogenic Bacteria Isolated from the Same Meat Small-Scale Facility. 1 - Screening and Characterization of the Antibacterial Compounds. Food Control, 17(6), 454-461.

Ananou, S., Muñoz, A., Gálvez, A., Martínez-Bueno, M. \& Maqueda, M. (2008). Optimization of Enterocin AS-48 Production on a Whey-Based Substrate. International Dairy Journal, 18(9), 923-927.

Bromberg, R., Moreno, I., Delboni, R. R \& Cintra, H. C. (2006). Características da bacteriocina produzida por Lactococcus lactis ssp. hordniae CTC 484 e seu feito sobre Listeria monocytogenes em carne bovina. Ciência Tecnologia Alimentos, 26(1), 135-144.

Cleveland, J., Montville, T. J.., Nes, I. F. \& Chikindas, M. L. (2001). Bacteriocins: safe, natural antimicrobials for food preservation. Int J Food Microbiol, 71(1):1-20

Dalié, D. K. D., Deschamps, A. M. \& Richard-Forget, F. (2010). Bactérias de ácido láctico - Potencial para controle do crescimento de fungos e micotoxinas: Uma revisão. Food Control, 21, 370-380.

Du, L., Liu, F., Zhao, P., Zhao, T. \& Doyle, M. P. (2017). Characterization of Enterococcus durans 152 bacteriocins and their inhibition of Listeria monocytogenes in ham. Food Microbiology, 68, 97-103.

Ferreira, A., Canal, N., Morales, D., Bopp, D. \& Corção, G. (2007). Characterization of enterocins produced by Enterococcus mundtii isolated from humans feces. Braz, Arch Biol Technol, 2(50), 249-258.

Fouquiér-Moreno, M. R., Callewaert, R., Devreese, B., Van Beeumen, J. \& De Vuyst, L. (2003). Isolation and biochemical characterisation of enterocins produced by enterococci from different sources. Journal of Applied Microbiology, 94, 214-229.

Furlaneto-Maia, L., Ramalho, R., Rocha, K. R. \& Furlaneto, M. C. (2020). Antimicrobial activity of enterocins against Listeria sp. and other food spoilage bacteria. Biotechnol Lett. doi.org/10.1007/s10529-020-02810-7.

Garriga, M., Hugas, M., Aymerich, T. \& Monfort, J. M. (1993). Bacteriocinogenic activity of lactobacilli from fermented sausages. Journal of Applied Microbiology, 75, 142-148.

Ghrairi, T., Frere, J. J., Berjeaud, M. \& Manai, M. (2008). Purification and Characterisation of Bacteriocins Produced by Enterococcus Faecium from Tunisian Rigouta Cheese. Food Control, 19(2), p. 162-169.

Hu, Y., Liu, X., Shan, C., Xia, X., Wang, Y., Dong, M. \& Zhou, J. (2017). Novel bacteriocin produced by Lactobacillus alimentarius FM -MM 4 from a traditional Chinese fermented meat Nanx Wudl: Purification, identification and antimicrobial characteristics, Food Control, 77, 290 -297.

Khan, H., Flint, S. \& Yu, P.L. (2010). Enterocins in food preservation. International Journal of Food Microbiology, 141, 1-10.

López, R. S., García, M. T., Abriouel H., Omar, N. B., Martínez-Cañamero, M. \& Gálvez, A. (2007). Semi-Preparative Scale Purification of Enterococcal Bacteriocin Enterocin EJ97, and Evaluation of Substrates for Its Production. Journal of Industrial Microbiology and Biotechnology, 34(12),779-785.

Lü, X., Yi, L., Dang, J., Dang, Y e Liu, B. (2014). Purification of novel bacteriocin produced by Lactobacillus coryniformis MXJ 32 for inhibiting bacterial foodborne pathogens including antibiotic -resistant microorganisms, Food Control, 46, 264 -271.

Luna, J. M., Rufino, R. D., Sarubbo, L. A. \& Campos, G. M. (2008). Produção de Biossurfactante em meio de baixo custo formulado com água do mar. Exacta, 6(2), $209-215$.

Mayr-Harting, A., Hedges, A. J. \& Berkeley, R. C. W. (1972). Methods for studying bacteriocins. Methods in Microbiology, 7A(4), 315-422

Motta, A. S. \& Brandelli, A. (2008). Evaluation of environmental conditions for production of bacteriocin-like substance by Bacillus sp. strain P34. World Journal of Microbiology and Biotechnology, 24(5), 641-646.

Oliveira, C. P. J., Siqueira-Júnior, P. \& Silva, J. A. (2012). Bacteriocinas Como Alternativa Na Conservação De Alimentos. Revista Verde de Agroecologia e Desenvolvimento Sustentável, 7(1), 09-15. 
Research, Society and Development, v. 10, n. 2, e1110212206, 2021

(CC BY 4.0) | ISSN 2525-3409 | DOI: http://dx.doi.org/10.33448/rsd-v10i2.12206

Ogaki, M. B., Rocha, K. R., Terra, M. R., Furlaneto, M. C. \& Furlaneto- Maia, L. (2016). Screening of the enterocin-encoding genes and antimicrobial activity in Enterococcus species. J Microbiol Biotechnol, 26:1026-1034.

Ozdemir, G. B., Oryasin, E., Biyik, H. H., Ozteber, M. \& Bozdogan, B. (2011). Phenotypic and genotypic characterization of bacteriocins in enterococcal isolates of different sources. Indian J Microbiol, 51(2):182-7.

Rivas, B., Moldes, A. B.., Domínguez, J. M. \& Parajó, J. C. (2004). Development of Culture Media Containing Spent Yeast Cells of Debaryomyces Hansenii and Corn Steep Liquor for Lactic Acid Production with Lactobacillus Rhamnosus. International Journal of Food Microbiology, 97(1), 93-98.

Rocha, K. R., Perini, H. F., Souza, C. M., Schueler, J., Tosoni, N. F., Furlaneto, M. C. \& Furlaneto-Maia, L. (2019). Inhibitory effect of bacteriocins from enterococci on developing and preformed biofilms of Listeria monocytogenes, Listeria ivanovii and Listeria innocua. World Journal of Microbiology and Biotechnology 35:96.

Salvucci, E., Rossiet, M., Colombo, A., Pérez, G., Borneo, R. \& Aguirre, A. (2019). Triticale flour films added with bacteriocin-like substance (BLIS) for active food packaging applications. Food Packaging and Shelf Life, 19, 193-199.

Tosoni, N. F., Perini, H. F., Terra, M. R., Katsuda, M. S., Furlaneto, M. C. \& Furlaneto-Maia, L. (2019) Antimicrobial activity of enterocin obtained from Enterococcus durans on Shiga-like toxin-producing Escherichia coli. Ciência Rural, Santa Maria, 49(9), e20190297.

Vázquez, J. A., González, M. P. \& Murado, M. A. (2006). Preliminary Tests on Nisin and Pediocin Production Using Waste Protein Sources: Factorial and Kinetic Studies. Bioresource Technology, 97(4), 605-613.

Yang, E., Lihua, F., Jiang, Y., Doucette, C. \& Fillmore, , S. (2012). Atividade antimicrobiana de bactérias lácticas produtoras de bacteriocinas isoladas de queijos e iogurtes. AMB Express, v.2,

Zendo, T., Koga, S., Shigeri, Y., Nakayama, J. \& Sonomoto, K. (2006). Lactococcin Q, a novel two-peptide bacteriocin produced by Lactococcus lactis QU 4. Appl Environ Microbiol, 72(5):3383-3389. 